\title{
DESAFIOS ORGANIZACIONAIS DO SÉCULO XXI: UMA INTRODUÇÃO AO FÓRUM SOBRE INOVAÇÃO, CAPACIDADES DINÂMICAS, CAPACIDADE DE ABSORÇÃO DO CONHECIMENTO E RELAÇÕES SIMBÓLICAS
}

Atualmente, é expressiva a quantidade de temáticas, fenômenos e discussões acerca de desafios organizacionais que se evidenciam na Administração como campo científico. Grande parte desses desafios conflui para quatro eixos principais: I. o desafio de inovar estrategicamente; 2 . a busca por vantagens competitivas por meio do desenvolvimento e da reconfiguração de capacidades dinâmicas; 3. a demanda pela articulação e absorção de conhecimento que visa a aprendizagem; e 4. o desafio de compreender o contexto organizacional e dar sentido à experiência subjetiva (simbolismo) de uma organização e de seus membros.

O primeiro desafio, de inovar estrategicamente, exige uma constante adaptação das organizações que pode ser promovida em relação a produtos, serviços, operações, processos e pessoas. Esse desafio requer, especialmente, o acompanhamento das constantes demandas e mudanças do ambiente externo (Baregheh, Rowley, \& Sambrook, 2009). As empresas brasileiras são tradicionalmente consideradas não propensas a inovar, muitas vezes experimentando dificuldades na gestão de tecnologia. Esforços nacionais datam da década de I970, lembrada pelas políticas de industrialização que estiveram focadas no estímulo à substituição de importações. Em nível empírico, há uma carência de informação e estudos sobre as práticas inovadoras de empresas nacionais. Essa lacuna está sendo minimizada gradualmente por estudos setoriais, regionais e análises de casos, o que nos tem permitido entender o comportamento de empresas no Brasil com maior profundidade (Nagano, Stefanovitz, \& Vick, 20I4).

O segundo desafio, quiçá considerado um dos mais prementes entre os estudos organizacionais, está na busca por vantagens competitivas por meio de capacidades dinâmicas. O conceito de capacidade dinâmica como fonte de 
vantagem competitiva motivou a propagação de estudos nos últimos anos, porém de maneira não homogênea e consensual, o que torna a necessidade de aprofundamento acerca do tema um desafio ainda maior. Atividades coletivas, por meio das quais a organização sistematicamente gera e modifica suas rotinas operacionais em busca de maior eficácia, são traços característicos de capacidade dinâmica (Zollo \& Winter, 2002).

Associado a essa conceituação está o conceito de capacidade de absorção, representado por um conjunto de rotinas organizacionais e processos estratégicos pelos quais as empresas adquirem, assimilam, transformam e exploram o conhecimento com a finalidade de criar valor e produzir uma capacitação dinâmica (Zahra, Sapienza, \& Davidsson, 2006). Essa definição nos leva a vislumbrar um terceiro desafio, que se refere à demanda pela capacidade de absorção (do inglês absorptive capacity). Segundo Cohen e Levinthal (I990), precursores de estudos sobre o tema, trata-se de um dos processos fundamentais de aprendizagem em uma organização, ou seja, a capacidade de adquirir conhecimento por meio do ambiente.

Todos os desafios mencionados estão atrelados a um quarto desafio, a importância de compreender como ocorrem as trocas subjetivas (simbólicas) dos atores sociais na construção da realidade organizacional.

Entender processos que ocorrem no contexto organizacional é, antes, entender os significados que o envolvem. Os indivíduos inseridos em uma realidade organizacional constroem definições dessa realidade, tendo como base a construção simbólica que serve como direcionadora para compreender esse contexto e agir sobre ele. As relações simbólicas são, portanto, um caminho para entender as sucessivas transformações no ambiente organizacional. Dependendo de como ela foi socialmente construída, uma relação simbólica pode ter múltiplas implicações organizacionais (Carrieri \& Saraiva, 2007).

Dada a necessidade de aprofundamento de investigação e de reflexões sobre tais tópicos, o objetivo do Fórum sobre Inovação, Capacidades Dinâmicas, Capacidade de Absorção do Conhecimento e Relações Simbólicas da Revista de Administração Mackenzie (RAM) foi reunir estudos que apresentam avanços recentes e racionalidades que contribuem para o entendimento desses desafios.

Para a preparação deste número, foi solicitado aos autores dos 24 trabalhos mais bem avaliados no XXVIII Simpósio de Gestão da Inovação Tecnológica da Associação Nacional de Pós-Graduação e Pesquisa em Administração (Anpad), realizado em Belo Horizonte (MG), em novembro de 20I4, que submetessem, para reavaliação, os artigos produzidos ao processo normal de blind review da RAM. Dessa solicitação, apenas I3 trabalhos foram submetidos. Três deles foram rejeitados no processo de desk review, apenas um foi avaliado a tempo de compor 
este número, e nove ainda estavam em fase de avaliação no momento desta edição final.

Assim, com o objetivo de não atrasar o cronograma de edição, foram incluídos quatro artigos já aprovados que tratavam de temas conexos com inovação. Além disso, foram incluídos mais três artigos sobre capacidade dinâmica, capacidade de absorção do conhecimento, relações simbólicas e motivação no trabalho voluntário.

Os oito artigos que compõem este fórum apresentam resultados de esforços acadêmicos no sentido de analisar, de modo teórico e empírico, os quatro desafios organizacionais supracitados. Dos oito trabalhos, cinco concentram-se no contexto de casos brasileiros, e três comunicam resultados de levantamento sistemático de literatura.

Neste fórum, o artigo "Relações entre fatores contextuais internos às organizações e a adoção de estratégias proativas e reativas de ecoinovações”, de Marlete Beatriz Maçaneiro e Sieglinde Kindl da Cunha, trata especificamente de estratégias de ecoinovação (inovações com ênfase no desenvolvimento sustentável), com o propósito de analisar as relações entre fatores contextuais internos às organizações e a adoção de estratégias de ecoinovação proativas e reativas, tendo como foco o setor de celulose, papel e produtos de papel. Os principais resultados apontam relacionamentos significativamente positivos entre o apoio da alta administração, a competência tecnológica e a formalização ambiental, com a definição de estratégias de ecoinovação proativas.

Em "Mapa do conhecimento em nanotecnologia no setor agroalimentar", Sibelly Resch e Milton Carlos Farina identificam e descrevem as pesquisas que envolvem a nanotecnologia no setor agroalimentar, a partir de trabalhos publicados na base de dados Scopus. O trabalho visa estimular a elaboração de políticas de apoio e fomento à nanotecnologia para o setor agroalimentar, e sugere temas de pesquisa para identificação do estágio atual dessas tecnologias no Brasil. A prospecção realizada pelos autores também contribui para a identificação de oportunidades de negócios para empresários brasileiros.

Apresentado na língua inglesa, o manuscrito "Capabilities, innovation and overall performance in Brazilian export firms", de José Ednilson de Oliveira Cabral, Arnaldo Fernandes Matos Coelho, Filipe Jorge Fernandes Coelho e Maria da Penha Braga Costa, examina, a partir das perspectivas da visão baseada em recursos (resource-based view - RBV) e da capacidade dinâmica, os efeitos interativos de capacidades de exploração e aproveitamento na inovação de produtos para os mercados externos e o desempenho global. Além disso, os autores testam o efeito moderador do dinamismo do mercado e o efeito do porte da empresa sobre essas relações. Na combinação desses construtos, o artigo 
propõe um modelo original, testado com dados de 498 empresas exportadoras brasileiras.

Partindo da estreita relação entre estratégias organizacionais e a prática da inovação, o artigo "A relação entre a estratégia de produção e a prática da inovação tecnológica: um estudo em uma empresa produtora de alumínio”, de Márcia Regina Neves Guimarães, Felipe Ferreira de Lara e Raissa Oliveira Peroba Trindade, analisa como a inovação tecnológica de produto e processo se insere no conteúdo da estratégia de produção de uma empresa produtora de alumínio da região de Sorocaba. Os autores observam que há, na empresa, uma maior ocorrência da inovação de processo do que da inovação de produto. Como prioridades competitivas, verifica-se a ênfase em flexibilidade e custo.

Outro trabalho que se concentra no desafio organizacional de inovar, elaborado por Gustavo Tomaz Buchele, Pierry Teza, Gertrudes Aparecida Dandolini e João Artur de Souza, é "Análise dos artigos qualitativos empíricos sobre métodos, técnicas e ferramentas para inovação". Consiste em uma análise de estudos relacionados à difusão e adoção de métodos, técnicas e ferramentas para inovação (MTF-Is). Os artigos analisados foram obtidos por meio de um levantamento sistemático realizado a partir das bases de dados Scopus e Web of Science. Os autores verificam a grande diversidade de MTF-Is utilizados pelas empresas estudadas. O estudo conclui ainda que a utilização de MTF-Is é importante para aumentar a competitividade e principalmente resolver problemas nas organizações.

Representando o desafio organizacional de compreender a experiência subjetiva (simbolismo) - e dar sentido a ela - de uma organização e de seus membros, o artigo "As relações simbólicas e a motivação no trabalho voluntário", de Kássia de Aguiar Salazar, Alfredo Rodrigues Leite da Silva e Letícia Dias Fantinel, visa entender as relações simbólicas que envolvem a motivação no trabalho voluntário, tendo como objeto de estudo a Associação Voluntárias da Apae (Avapae) de Venda Nova do Imigrante. O trabalho se legitima na relevância de estudar as organizações por meio de abordagens voltadas para os simbolismos organizacionais e a construção da realidade. A motivação, observada pelos autores por meio dos significados da participação voluntária, tem como base o sentimento de fazer parte de algo ou transformar um meio, tendo um papel importante naquela tarefa social.

Versando sobre capacidades dinâmicas, apresentamos o trabalho "Análise das publicações sobre capacidades dinâmicas entre I992 e 20I2: discussões sobre a evolução conceitual e as contribuições dos autores de maior notoriedade na área", de André Luís Janzkovski Cardoso e Heitor Takashi Kato. Os autores apresentam as contribuições dos principais estudos para o desenvolvimento da 
abordagem das capacidades dinâmicas e discutem uma evolução conceitual. É um estudo bibliométrico com tratamento dos dados por meio de escala multidimensional e análise de rede. Na análise da evolução da abordagem, consideram-se os diferentes conceitos e as proposições teórico-empíricas apresentados por autores de maior notoriedade na área, em diversos estudos sobre o tema.

O último artigo é dedicado ao estudo da capacidade de absorção de conhecimento, cujos autores são Graziele Ventura Koerich, Éverton Luís Pellizzaro de Lorenzi Cancellier e Rafael Tezza. O conteúdo do manuscrito "Capacidade de absorção, turbulência ambiental e desempenho organizacional: um estudo em empresas varejistas catarinenses" verifica a influência da capacidade de absorção no desempenho organizacional sob diferentes condições de turbulência ambiental. Trata-se de um estudo descritivo do tipo levantamento ou survey. A pesquisa foi composta por empresas de varejo na região da Grande Florianópolis. Os resultados a partir de 230 empresas varejistas mostram que a capacidade de absorção tem efeito positivo sobre o desempenho organizacional.

Registramos os nossos agradecimentos pelo convite do editor acadêmico da Revista de Administração Mackenzie, Silvio Popadiuk, e a nossa satisfação em fazer parte da edição deste fórum. Aos avaliadores de todos os artigos aqui publicados, o nosso reconhecimento e gratidão.

Que o ensejo de leitura dos trabalhos publicados traga motivações para novos estudos e boas reflexões e apreciações aos estudiosos dos campos aqui abordados.

THAIS ELAINE VICK Editora convidada Doutora em Engenharia de Produção pela Escola de Engenharia de São Carlos da Universidade de São Paulo (Eesc-USP) e pesquisadora da Queen Mary University of London, School of Business and Management.

E-mail: thavick@sc.usp.br

\section{DENISE DEL PRÁ NETTO MACHADO}

Editora convidada Doutora em Administração de Empresas pela Fundação Getulio Vargas - (Eaesp/FGV). Professora e pesquisadora da Universidade Regional de Blumenau (Furb), atuando nos programas de Pós-Graduação em Administração (mestrado) e Ciências Contábeis e Administração (mestrado e doutorado), e membro do comitê científico da área de Gestão de Ciência, Tecnologia e Inovação (GCT) da Anpad. E-mail: profadenisedelpra@gmail.com 


\section{FERNANDO GOMES DE PAIVA JUNIOR}

Editor convidado

Doutor em Administração pela Universidade Federal de Minas Gerais (UFMG). Professor e pesquisador do Lócus de Investigação em Economia Criativa do Programa de Pós-Graduação em Administração da Universidade Federal de Pernambuco (UFPE) e membro do comitê científico da área de Gestão de Ciência, Tecnologia e Inovação (GCT) da Anpad. E-mail: fernando.paivajr@gmail.com

\section{CLEBER CARVALHO DE CASTRO}

Editor convidado

Doutor em Agronegócios e mestre em Administração pela Universidade Federal do Rio Grande do Sul (UFRGS). Professor e pesquisador da Universidade Federal de Lavras (Ufla) e líder do Grupo de Estudos em Redes, Estratégia e Inovação (Gerei) e do tema "Inovação, Cooperação e Redes Organizacionais" da área de Gestão de Ciência, Tecnologia e Inovação (GCT) da Anpad. E-mail: clebercastrouai@gmail.com

\section{REFERÊNCIAS}

Baregheh, A., Rowley, J., \& Sambrook, S. (2009). Towards a multidisciplinary definition of innovation. Management Decision, 47(8), I323-I339.

Carrieri, A. de P., \& Saraiva, L. A. S. (2007). Introdução. In A. de P. Carrieri \& L. A. S. Saraiva (Orgs.). Simbolismo organizacional (pp. I-I2). São Paulo: Atlas.

Cohen, W., \& Levinthal, D. (I990). Absorptive capacity: a new perspective on learning and innovation. Administrative Science Quarterly, 35(I), I28-I52.

Nagano, M. S., Stefanovitz, J., \& Vick, T. E. (20I4). Innovation management processes, their internal organizational elements and contextual factors: an investigation in Brazil. Journal of Engineering and Technology Management, 33, 63-92.

Zahra, S. A., Sapienza, H. J., \& Davidsson, P. (2006). Entrepreneurship and dynamic capabilities: a review, model and research agenda. Journal of Management Studies, 43(4), 9I7-955.

Zollo, M., \& Winter, S. G. (2002). Deliberate learning and the evolution of dynamic capabilities. Organization Science, 13, 339-351. 